\title{
UTILIZATION OF INDIGENOUS ARABLE CROP STORAGE AND PRESERVATION TECHNOLOGY IN NIGERIA
}

\author{
H. F. B. FABORODE *, A. O. AJAYI
}

\author{
Address: \\ Department of Agricultural Extension and Rural Development, Obafemi Awolowo University, Ile-Ife, Nigeria \\ * Corresponding author e-mail: hfbfaborode@yahoo.com
}

\begin{abstract}
Farmers and their technology remain central to national food security and agricultural development in Nigeria. There is growing concern that the technologies used by farmers for storage and preservation of arable crops may constitute impediments to rural agricultural development. The study assessed farmers' utilization of indigenous storage and preservation technologies for arable crops with a view to expanding technology options. Multi-staged sampling procedure was used to obtain data from 240 practicing arable crop farmers. The results revealed that 15 technologies were utilised with variations between crops and gender. The constraints to technology utilisation and reasons for usage were also identified. Results of regression analysis revealed that years of formal education, years of farming experience and farm size significantly influenced technology utilization in arable crops in Nigeria. There was a low extent of utilization and most farmers were dissatisfied with indigenous technologies despite few available alternatives.
\end{abstract}

Keywords: farms, indigenous technology, storage, agricultural development, Nigeria JEL: Q01, Q16

\section{INTRODUCTION}

In most developing countries, Nigeria inclusive, a substantial proportion of agricultural produce is stored and preserved at the farm level in traditional storage structure inherited from generations (Nwakiti \& Makurdi, 1989; Olumeko, 1996; Pasu, 1998; Adekunle \& Nanbita, 2006; Aworh, 2008; Adiaha, 2017). The technologies used are determined by location and made of a wide variety of locally sourced materials. Sekumade and Oluwatayo (2009); Alonge, (2011); Hodges, Buzby \& Bennett (2011) identified five major generally used traditional grain storage technologies in Nigeria as an open field, domestic structure, platform or tree structure, pit and earth (mud) storage structure. These indigenous technologies have been improved through indigenous information systems which are dynamic and continually influenced by internal creativity, observation and experimentation (Kolawole, 2001). Thus, indigenous storage and preservation are critical to sufficient availability and accessibility to arable crops which include yam, cassava, legumes, grains, and vegetables; the bulk of which is produced by farmers in Nigeria.

In the past, farmers' arable crop produce was basically used for household meal, preservation for subsequent planting season, as gifts during special occasions, such as marriage ceremonies while the economic reason was of little importance. More importantly, there was good weather, the available land could conveniently support the population and every household was food sufficient. However, there is growing concern that the use of indigenous arable crop storage and preservation technology may no longer be adequate to meet the present needs due to prevailing circumstances. These include the global economic recession, climate variability as well as increase in Nigeria's population from 55.7 million in the 60's (DNS, 1995) to 140 million in the last National Population Census (NPC, 2006). These have contributed to rural-urban migration, massive youth unemployment and food insecurity in Nigeria. Food utilization and nutritional well-being of many households in Nigeria are of relatively low quality with about 60.8 percent of Nigerians malnourished (National Bureau of Statistic, 2007; Labadarios et al., 2011; FAO, 2012; Ifeoma \& Agwu, 2014). The un-abating hunger and malnutrition make rural agriculture an essential concern. The use of effective storage and preservation technology is germane to food availability at the required quantity and quality in Nigeria.

Hence, successive governments, local and international aid agencies have engaged conscious efforts through interventions with programmes and projects to enhance agriculture. Incidentally, such interventions were mainly directed towards production enhancement activities with little attention to crop storage and preservation technologies that could enhance adequate security of what is produced at required quantity, quality and pricing throughout the year. Thus, the high level of wastage in crop production remains an issue (Ivbijaro, 1989; Singh and Satapathy, 2003) till now in Nigeria. This is not peculiar to Nigeria but a challenge to SubSaharan Africa (FAO, 2010; FAO, 2014). Therefore, irrespective of what interventions that have been made, farmers and their indigenous technology remain central to national food security and agricultural development. 


\section{Conceptual framework}

The article is conceptualized within the context of Indigenous Knowledge System (IKS) and how the outcome of its assessment can be used to evolve better technology for optimal performance in agriculture. Literature abounds on IKS with diverse definitions of the concept partly due to the differences in background and perspectives of various writers, ranging from Sociology, Anthropology, Engineering and Science. Traditional/Indigenous knowledge system is defined as the knowledge that is unique to a given culture or society and use as a basis for local level decision making in agriculture, health care, food preparation, preservation, education, natural resources management and a host of other activities (Chikaire, et al., 2012). Mercer et al. (2007) and Agea et al. (2008) defined indigenous knowledge to include the social and natural well-being that are continually influenced by local creativity, experimentation and contact with external systems. It is also defined as the systematic body of knowledge acquired by local people through the accumulation of experience, informal and intimate understanding of the environment in a given culture (World Bank, 2008). Titilola et al. (1994); Verma (2004); Gervais (2005); Magni (2016) identified the attributes of IKS to include serving as a springboard to technological development and being dynamic rather than static. Therefore, the present situation in which indigenous technology is neglected or used without modification is an aberration that should be addressed.

Regular assessment of technology utilization occupies a central position in any strategy to impact agricultural development. Knowing and understanding existing technologies used by farmers will enhance their perfection, relevance to farmers' situation and promote acceptability by intending users. Therefore, one of the strategies for developing the agricultural sector is to tap the potentials from Indigenous Knowledge. This thinking has gained recognition through many initiatives including the 1997 United Nations Conference on Environmental Development (CIESIN Thematic Guide, 1997). Tsiko (2009) opined that focusing IKS helps in the identification of gaps in local knowledge, interventions required and the removal of harmful practices recognized in existing practices while to be replaced with better practices. In recent years, development agencies and researchers have come to recognize that efforts carried out exclusive of the needs, location and culture of the target audience often failed to bring about appropriate and sustainable development and that the needs, values, knowledge and capabilities of such countries form an essential basis for effective development programme (UNESCO, 2007). Thus, the IKS is critical to the survival and future of rural communities as they endeavour to maintain their livelihoods under difficult environmental conditions (Parrotta \& Agnoletti, 2007).

The relevance of assessing the utilization of existing indigenous technologies by arable crop farmers to ensure the development of better technology options that could meet the needs of farmers is imperative. It is against this background that this study was carried out to assess the extent of utilization of indigenous technology for storage and preservation of arable crops by farmers with a view to focus on the need to expand farmers' technology options for agricultural development that would enhance or facilitate sustainable food production and security in Nigeria. The respondents' views on identified variables related to indigenous technologies used for storage and preservation of arable crops were examined as well as the utilization of indigenous technology by gender and crops. The constraints encountered by farmers were examined while the extent of utilization was determined.

\section{MATERIALS AND METHODS}

\section{Study Area}

The study was carried out in Ondo state, located in the South West of Nigeria which has its headquarters in Akure. It has a land area of 14,769 square kilometres with a population of $3,441,024$ people (2006 census). The temperature (ranges between $21^{\circ} \mathrm{C}$ and $29^{\circ} \mathrm{C}$ ) with relatively high humidity (of about $78 \%$ ) and an annual rainfall (varying from $1,150 \mathrm{~mm}$ to $2,000 \mathrm{~mm}$ ). The state is an agrarian state whose inhabitants depend mainly on agriculture for livelihood and has 18 Local Government Areas. For effective and efficient administration of Agricultural Development Project (ADP), the state is divided into two zones namely Ondo zone having 9 local government areas (LGA) and Owo zone also having 9 LGA.

\section{Sampling Procedure}

Multi-stage sampling procedure was used to select 240 respondents for the study. The first stage was the purposive selection of three LGAs from the major arable crop producing LGAs from each of the two zones. The second stage involved the use of simple random sampling to select two villages from each of the six chosen LGAs, making a total of twelve villages. Lastly, simple random sampling technique was used to select 20 farmers representing 25 percent of the major arable crop producers in selected farmers' group from the list of ADP farmers registered in each of the selected villages to give a total of 240 respondent farmers.

Also, periodic observation of storage and preservation of arable crops was carried out for 12 months to cover the two distinct climatic seasons on the farmers' fields and during transit in vehicles conveying produce to both farmers' residence and markets. In addition, three key informants identified through snowball technique (a technique whereby an identified respondent, serves as a link to other needed respondents) were selected from each of the 12 villages studied to make a total of 36 leaders of prominent market associations, farmers' groups and communities.

Interview schedule and key informant interview guide were developed in line with the objectives of the study and properly validated through jury method. It was subjected to test and re-test method for reliability.

Dependent and independent variables were the two broad variables investigated in the study. The dependent variable was farmers' utilization of indigenous arable crop storage and preservation technology. The extent of utilization was measured with the use of responses to 
standardized selected statements on a five-point scale (Very often (4), Often (3), Sometimes used (2), Rarely used (1) and Not used (0)). The total score was divided by the number of the population studied to arrive at the calculated mean as the extent of utilization for each technology. Two (2) was calculated as the mid score. The midpoint was calculated as the addition of all the values of the five-point scale (10.0) divided by 5, (the number of rated scale used), making 2.0. Technologies scored above 2.0 had high and those below it had low utilization respectively. The independent variables of the study were the selected variables related to indigenous technology, farmer's constraints to technology utilization, utilization of technology by gender and by crops were measured directly with the absolute values given by the respondents.

The total mean scores for all the technologies were divided by the number of technologies studied to arrive at the grand mean score. The scores of the respondents were used for regression analysis.

Frequency, percentages, ranked mean, figure and grand mean scores were used to summarize the data obtained. Multiple regression analysis was used to determine the variables which significantly influence farmers' decision to utilize indigenous arable crop storage and preservation technologies.

\section{RESULTS AND DISCUSSION}

\section{Selected variables related to indigenous technologies}

Table 1 shows the frequency and percentage distribution of farmers by types of storage and preservation of arable crops used. All the farmers used indigenous storage and preservation technologies while only a few used alternative technologies. This implies that though a few farmers used a combination of both types, they however, depended more on indigenous crop storage and preservation technologies.

All the respondents used the indoor while fewer farmers used the outdoor technologies of storage and preservation (Table 1). Farmers' preference for the indoor technologies was not based on the best option but on fear of pilferage of farm produce. Based on personal observation, the small residential houses where the indoor storage and preservation technologies were kept could only accommodate small storage facilities. In line with the observations is the following excerpt from the key informant interview conducted in the communities: ,...we prefer to keep our farm produce in these small houses where we stay, thieves often come to carry away most of the farm produce left outside. The outdoor structure, are better, but we often rush to sell our farm produce kept outside even when there is a glut in the market to avoid total loss to the thieves. In the past, things could be left outside without fear...". Although, the indoor type of technology was used by most farmers, evidently, the outdoor type would better serve their needs in terms of space, convenience, health safety and effectiveness.

Further analysis revealed several reasons for farmers' utilization of indigenous technologies. All the respondents used indigenous technologies because they are affordable and have no harmful effects on their crops while majority indicated that indigenous technologies do not alter traditionally assigned gender roles, they are easy to use, available everywhere, environmentally friendly and compatible with farmers' culture.

These reasons are some of the benefits of indigenous technology which represent the valued characteristics that farmers would like to see in any improved technology developed to enhance rural agriculture and economic growth. However, despite the wide-spread usage of indigenous technology by farmers only a few expressed satisfaction with their performance. This is suggestive of the fact that the farmers were yearning for improvement on the technologies used for storage and preservation of arable crops.

Table 1: Distribution of respondents by variables related to storage and preservation technologies

\begin{tabular}{|c|c|c|}
\hline **Selected variables & $\begin{array}{l}\text { Frequency } \\
(n=240)\end{array}$ & $\%$ \\
\hline \multicolumn{3}{|l|}{ Types of technologies used } \\
\hline Indigenous & 240 & 100 \\
\hline Alternative & 28 & 11.7 \\
\hline \multicolumn{3}{|l|}{ Mode of storage and preservation } \\
\hline Indoor & 240 & 100 \\
\hline Outdoor & 17 & 7.1 \\
\hline \multicolumn{3}{|c|}{ Reasons for utilization of indigenous technologies } \\
\hline They are affordable & 240 & 100 \\
\hline They are inherited and must be preserved & 131 & 54.6 \\
\hline They are compatible with our culture & 142 & 59.2 \\
\hline They are available everywhere & 188 & 78.3 \\
\hline They satisfactorily preserve our crops & 78 & 32.5 \\
\hline There are no better alternatives & 190 & 79.3 \\
\hline $\begin{array}{l}\text { Crops kept in them do not contain } \\
\text { harmful substances }\end{array}$ & 240 & 100 \\
\hline They are easy to use & 212 & 88.3 \\
\hline $\begin{array}{l}\text { They do not alter traditionally assigned } \\
\text { gender role }\end{array}$ & 142 & 59.2 \\
\hline They are environmentally friendly & 150 & 62.5 \\
\hline
\end{tabular}

During the course of this investigation, periodic observation over a 12 month period in the farmers' farm and of vehicles conveying farm produce revealed that many crops (tomatoes, pepper, vegetables and yam) were kept in bags, baskets, and bare floor on the preceding day to market days in the communities. Many of the farm produce were rotting with no visible ways to prevent further spoilage. The observation revealed the need to critically overhaul the storage and preservation practices of farmers to sustain the increase in crop production for food security.

Farmers' utilization of indigenous technology by gender In Figure 1, the males utilized all the 15 identified storage and preservation technologies while the females used 14 . Numerically, both gender used high numbers of indigenous technologies. Furthermore, results revealed that though the females recorded slightly lower number of technologies, more females $(\geq 71.9 \%)$ utilized 12 out of the 14 technologies while fewer males $(\geq 57.2 \%)$ utilized only 7 of the 15 technologies. Thus, eight of the technologies were utilized by between 23.1 to 43.8 percent males. These results imply that more females utilized the 
indigenous storage and preservation technologies widely than their male counterpart. This is an indication of technology gap in favour of the female gender. This finding may not be unconnected with the fact that storage and preservation of arable crops were traditionally assigned roles of the female gender as store keepers and food handlers for the family.

However, more males (96.2\% and $87.5 \%)$ utilized yam barn and maize cribs respectively, while only 25 percent of females utilized maize crib and none of them used yam barn. This trend could also be explained against the background that the two crop specific technologies mainly used by the male gender were often used to store crops for purposes other than domestic use. For instance, they were used to store farm produce for sale, gifts during important festivals and for planting in the next season. Also, the finding revealed that indigenous technologies mostly used by the females were common household structure which did not require additional cost or energy like the maize cribs and yam barn. This finding corroborates the previous work by Soetan, Ayinde and Koledoye (2013) that the implements used by women are often constrained by their limited accessibility to resources.

Therefore, any improvement on indigenous technologies used by farmers must consider the culture and the resources available to the farmers in order to enhance equal gender participation in storage activities. This view was supported by a woman leader in one of the excerpts from the key informant interview: "...most improved technologies are not affordable to women and so the men often take over our roles as the main source of storage and preservation of farm produce when new technologies are introduced. What can we do than continue to use our traditional practices in order to sustain our families?"

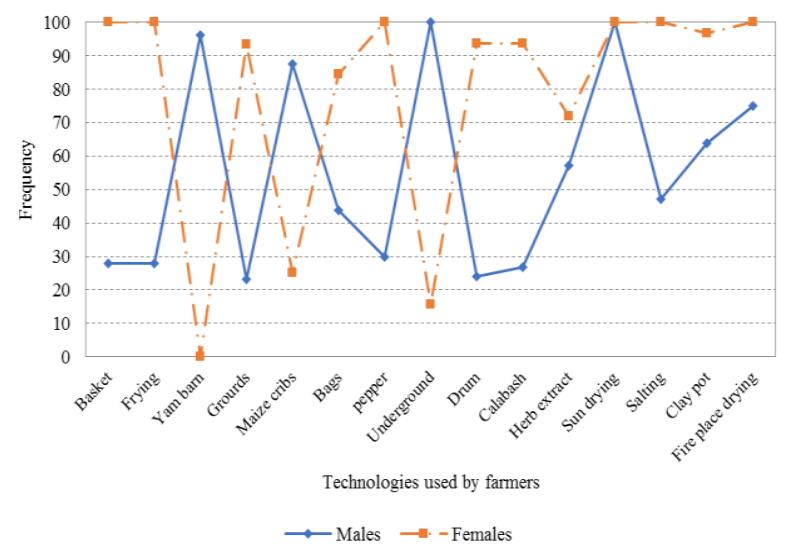

Figure 1: Distribution of farmers' utilization of indigenous technologies by gender

Source: Field survey, 2009.

\section{Technology utilization by crops}

Results (Table 2) show that 9 of the indigenous technologies were used for storage and preservation of maize, 8 for yam and cassava each, 7 for pepper, while both tomatoes and leafy vegetables had 5 each. These findings revealed unequal technology utilization between crops. Obviously, most crops despite their relevance to the family nutritional needs and national food security were produced without adequate storage and preservation. This probably accounted for common high incidence of high calorie food intake in rural communities (particularly during off-season periods), at the expense of other mineral-rich food intake. Several authors (WHO, 2003; Fasoyiro \& Taiwo, 2012; UNICEF/WHO/World Bank 2013) linked this with the malnutrition of children. This trend of unequal technology utilization for crop storage and preservation if not checked may lead to loss of indigenous technologies in the storage of some crops as the elders are dying without passing their knowledge to succeeding generation.

Further analysis also revealed individual crop percentage grand mean scores for technology utilization with the highest for maize. However, all the six crops had very low individual grand mean scores ranging from 2.4 to 29.4 percent. This implies very low technology utilization for the crops. Notably, the two important findings revealed are technology gap between crops and relatively low utilization of technology in all the 6 crops investigated. The following excerpt is from the key informant interview to buttress the finding: “... I stopped producing vegetables and tomatoes because there are no good storage and preservation facilities for them. Three years ago, I planted improved seedlings and had bountiful harvest only to be sold at giveaway prices for lack of storage provision. I prefer buying for my family consumption even when I cannot afford enough. We need help in this area...".

The findings imply that inadequate crop storage and preservation constitute a challenge to agricultural development in Nigeria which requires adequate attention. Similar findings were reported by FAO (2010); FAO (2011); IFAD, WFP \& FAO (2012) that lack of welldeveloped storage infrastructure contributes to the massive spoilage of food on the journey to consumers.

Also evident from the results of the study is that many indigenous technologies were identified for storage and preservation of arable crops in the study area, some of which are no longer in use. Therefore, the findings could provide a baseline data for further study on archival preservation of technologies that are going into extinction and policy formulation for research and development of improved technologies for rural agriculture.

\section{Types of technology used for arable crop storage}

All the respondents indicated the existence of both storage types of indigenous crop storage and preservation technology with the indoor type having a mean score of 1.8 out of a maximum score of 4.0 while the outdoor scored only 1.1 for the extent of utilisation (Table 3 ). This implies that though the indoor technology were more utilised, it however shows low extent of storage utilisation by farmers. The findings of this study agreed with the reports of Arowolo (2010) that many indigenous technologies domiciled in Africa, Nigeria inclusive needs to be jealously protected and packaged for the public good. 


\section{Indigenous technologies and extent of utilization}

Table 4 revealed that farmers utilized all the 15 identified indigenous technologies for arable crop storage and preservation. Eight technologies (sun-drying, underground storage, yam barn, maize crib, fire-place drying, clay pot, herb extract and salting) were used by most farmers. The remaining 7 technologies were used by fewer farmers ( 32.5 to $37.5 \%$ ). The findings showed that farmers utilized various indigenous storage and preservation technologies, but some were more utilized than others. Studies by Negi \& Solanki (2015) reported the variations in the use of herb extracts $(100 \%)$, gourd/tumri (78 \%), storage bags $(67 \%)$, salt (49\%) and lime with wood ash $(22 \%)$ as indigenous storage methods used by farm families of Kumaon region. The results of this study corroborates the findings of Abdullahi et al. (2016) who found airtight container, herb extract, house roof, finger pepper and salting as the most effective indigenous storage methods for cowpea while frying and use of ash were least effective. Also, the findings of this study firmly support the reports by Verma, Roy \& Swarnalatha (2005) on eco-friendly grain storage structure in India and reported hak (a cone shaped storage basket) as an extensively used storage structure in the hill zone of Assam. The non-utilization of many of the technologies by most respondents implies that they were either rushing to sell their farm produce to avoid total spoilage or not producing enough for storage. Similar results were reported by Ajani \& Onwubuya (2012) who assessed the utilisation of indigenous maize storage practices and found maize crib, fire place drying and bare floor as the dominant indigenous storage practices. The authors also reported that non-utilisation of indigenous storage could either be due to rushing to sell their produce when fresh to prevent spoilage or not producing enough for storage.

Specifically, sun-drying was the only technology with high mean score of 2.9 out of a maximum score of 4.0 expected for each technology utilisation and also the only technology above the midpoint of 2.0 which implies high extent of technology utilization. However, despite free use with no cost attached and the popularity of this technology among farmers, one basic challenge associated with the usage is its total dependent on weather which is seasonal and vulnerable to climate variability. Nigeria enjoys two predominant weather seasons (rain and dry). The raining season exclusive of weather variability is between the months of April and October while the dry season is November to March. Notably, most arable crops (yam, maize, tomatoes and leafy vegetables) are grown, harvested, preserved and stored during the rain because rural agriculture in Nigeria is rain-fed. Hence, for effective, efficient and cheap storage and preservation of farm produce, there is the need for alternatives or better management of this natural resource (sun) so that it could be used throughout the year. Thus, exploiting solar energy conservation for farmers' use will reduce farmers' vulnerability to variability in weather and enhance effective use of the sun throughout the year.

Table 2: Distribution of respondents' by storage and preservation technologies utilized by farmers most preferred arable crops

\begin{tabular}{|c|c|c|c|c|c|c|}
\hline Technologies & $\begin{array}{l}\text { Maize } \\
\text { F (\%) }\end{array}$ & $\begin{array}{c}\text { Yam } \\
\mathrm{F}(\%)\end{array}$ & $\begin{array}{c}\text { Cassava } \\
\mathrm{F}(\%)\end{array}$ & $\begin{array}{c}\text { Tomatoes } \\
\text { F }(\%)\end{array}$ & $\begin{array}{c}\text { Vegetables } \\
\mathrm{F}(\%)\end{array}$ & $\begin{array}{c}\text { Pepper } \\
\text { F }(\%)\end{array}$ \\
\hline Baskets & $90(37.5)$ & $47(19.58)$ & $31(12.92)$ & $83(34.58)$ & $17(7.08)$ & $5(2.5)$ \\
\hline Frying & - & - & $90(37.5)$ & - & - & - \\
\hline Yam barn & - & $200(83.3)$ & - & - & - & - \\
\hline Gourds & $78(32.5)$ & - & - & - & - & $39(16.5)$ \\
\hline Maize crib & $190(79.2)$ & - & - & - & - & - \\
\hline Bag & $97(40.420$ & $78(32.5)$ & $88(36.67)$ & - & $6(2.5)$ & $11(4.58)$ \\
\hline Pepper & $91(27.92)$ & - & - & - & - & - \\
\hline Underground storage & - & $163(67.92)$ & $101(42.08)$ & - & - & - \\
\hline Drum & $80(33.33)$ & - & $11(4.58)$ & - & - & $22(9.17)$ \\
\hline Calabash & $49(20.42)$ & $38(15.83)$ & $41(17.08)$ & $22(9.170$ & $16(6.67)$ & $31(12.92)$ \\
\hline Herb extract & - & $142(59.17)$ & - & - & - & - \\
\hline Sun drying & $240(100.0)$ & $62(25.83)$ & $89(37.08)$ & $21(8.75)$ & $17(7.08)$ & $34(14.14)$ \\
\hline Salting & - & - & - & - & - & - \\
\hline Clay pot & - & - & - & $89(37.08)$ & - & $167(44.58)$ \\
\hline Fire place & $167(69.58)$ & $22(9.17)$ & $31(12.92)$ & $41(17.08)$ & $31(12.92)$ & - \\
\hline Grand $(\%)$ mean of crop & 29.4 & 21.0 & 13.4 & 7.1 & 2.4 & 6.9 \\
\hline
\end{tabular}

Note: $\mathrm{F}=$ frequency, \%= Percentage

Source: Field survey, 2009

Table 3: Distribution of respondents by types of technology used for arable crop storage and preservation

\begin{tabular}{lccccccc}
\hline & Utilisation & \multicolumn{3}{c}{ Extent of usage } & & & \\
Types of technology & Frequency & $\%$ & Very often & Often & Rarely used & Not used & Mean \\
\hline Outdoor & 240 & 100 & $2(0.83)$ & $80(35.83)$ & $91(37.92)$ & $61(25.42)$ & 1.1 \\
Indoor & 240 & 100 & $19(7.92)$ & $160(66.67)$ & $61(25.42)$ & - & 1.8 \\
\hline
\end{tabular}

Source: Field survey, 2009 
Table 4: Distribution of respondents by extent of utilisation of indigenous arable crop storage and preservation technology

\begin{tabular}{llccccccc}
\hline Technologies & Utilization & \multicolumn{9}{c}{ Extent of usage } & \multicolumn{3}{c}{} \\
used & Frequency & $\%$ & Very often & Often & Rarely used & Not used & Mean & Ranked mean \\
\hline Sun-drying & 240 & 100 & 80 & 86 & 49 & 25 & - & 2.9 \\
Fire-place drying & 188 & 78.3 & 20 & 27 & 101 & 40 & 52 & 1.7 \\
Bags & 118 & 49.2 & 36 & 77 & 5 & - & 122 & 1.6 \\
Basket & 90 & 37.5 & 82 & 4 & 4 & - & 150 & 1.5 \\
Drum & 80 & 33.3 & 62 & 16 & 2 & - & 160 & 1.3 \\
Underground & 212 & 88.3 & - & 9 & 9 & 194 & 28 & 1.0 \\
Yam barn & 200 & 83.3 & 6 & 7 & 2 & 185 & 40 & 0.9 \\
Maize crib & 190 & 79.2 & 1 & 10 & 4 & 175 & 50 & 0.9 \\
Herb extract & 142 & 59.2 & 7 & 3 & 41 & 91 & 98 & 0.9 \\
Clay pot & 164 & 68.3 & 1 & 3 & 29 & 128 & 76 & 0.8 \\
Pepper & 94 & 39.2 & 21 & 8 & 13 & 52 & 146 & 0.8 \\
Frying & 90 & 37.5 & 16 & 13 & 21 & 40 & 150 & 0.8 \\
Salting & 130 & 54.2 & - & 3 & 4 & 123 & 110 & 0.6 \\
Calabash & 86 & 35.5 & - & - & 28 & 58 & 154 & 0.5 \\
Gouges & 78 & 32.5 & 1 & - & 3 & 74 & 162 & 0.4 \\
Grand Mean & & & & & & & & 1.1
\end{tabular}

Source: Field survey, 2009

Furthermore, only five technologies were scored above the minimum point of 1.0 , while most (9) technologies scored between 0.4 and 0.9 out of a maximum of 4.0 points expected for each technology. Hence, the grand mean score for the extent of utilization for all the technologies was 1.1 points, which signifies low extent of utilization in all the technologies. The low extent of utilization notwithstanding, indigenous technologies remain the dominant method of storage and preservation of farm produce used by farmers.

\section{Constraints experienced by farmers in technology utilization}

16 constraints to the utilization of indigenous storage and preservation technologies were identified and ranked (Table 5). Obviously, the farmers performed their roles as major arable crop producers under many constraints which have limiting effects on their efficiency. All the respondents viewed theft and short storage duration as leading constraints while most respondents listed high storage losses, rats, termite infestation, mould, excessive sprouting and insect infestation as constraints. Fewer farmers $(16.7 \%$, to $37.1 \%)$ listed low viability of seeds, inadequate capacity, fire and unfavourable weather as constraints to the effectiveness of indigenous technologies utilized. Incidentally, illiteracy and finance ranked lowest (15th and 16th) and were not viewed as serious challenges to utilization of indigenous technologies. This is not surprising since most of the indigenous technologies were home or community initiatives learned from childhood through socialization with little or no financial requirements. Notably, most constraints (14 out of 16) identified by respondents focused on farmers concern about crop losses which according to extant literature is enormous (Arinze and Oyi, 1989, and Mbuk et al., 2011; Gustavsson et al., 2011; Lipinski et al., 2013).

The effectiveness of any storage technology can be measured in terms of how much of losses it could reduce. Therefore, the lower the losses, the more effective the technology is adjudged to be. The inference from the above findings is that farmers were not satisfied with certain performances of indigenous technologies. Thus, if farmers are to receive adequate returns for their labour, they must be efficient producers and suffer less losses of farm produce. Hence, appropriate steps (such as improvement on existing technologies) must be taken to address the challenges and provide farmers with several alternative technologies to choose from.

Variables influencing utilization of indigenous storage and preservation technologies

Multiple regression analysis was used to analyse the determinants of utilization of indigenous technology among farmers in the study area. The findings revealed that strong relationship $(\mathrm{R}=0.81)$ exists between utilization of indigenous storage and preservation technologies and some variables. The significant variables were able to explain about 65.6 percent of the variation (Adjusted $\mathrm{R}^{2}=0.656$ ) in the utilization of identified technologies with the F-value of 371.321 ; at $\mathrm{p} \leq 0.05$. This further confirmed that relationship exists between utilization of indigenous storage and preservation technologies and the significant variables. Specifically, out of the eight variables regressed with utilization of indigenous storage and preservation technologies, six of them were found to be significant. The findings revealed that age $(b=0.174)$, years of formal education $(b=0.225)$, number of valued technology characteristics $(b=-0.029)$, monthly income $(b=-0.14)$, number of information sources $(b=0.05)$ and number of crops planted $(b=-0.03)$ were the important predictors of indigenous storage and preservation technology utilization among farmers in the study area (Table 6). The results implied that older people are custodian of indigenous technologies. This report corroborates the earlier findings reported by UNESCO (2009); Roos, Chigeza \& Van Niekerk (2010) that the older people knows and use more indigenous technologies than the younger people. 
Table 5: Distribution of respondents by constraints to utilization of indigenous storage and preservation technologies

\begin{tabular}{lccc}
\hline Constraints & Frequency & Percentage & Rank \\
\hline Theft & 240 & 100.0 & $1^{\text {st }}$ \\
Short storage duration & 240 & 100.0 & $1^{\text {st }}$ \\
High storage losses & 239 & 99.6 & $3^{\text {rd }}$ \\
Indigenous technologies are prone to rat infestation & 233 & 97.1 & $4^{\text {th }}$ \\
Indigenous technologies are prone to termites infestation & 226 & 94.2 & $5^{\text {th }}$ \\
It is prone to growing of moulds on stored crops & 219 & 91.3 & $6^{\text {th }}$ \\
It encourages excessive sprouting & 218 & 90.8 & $7^{\text {th }}$ \\
Insect infestation of stored crops & 216 & 90.0 & $8^{\text {th }}$ \\
Inadequate extension advice & 189 & 78.8 & $9^{\text {th }}$ \\
Indigenous technologies are not moisture proof & 160 & 66.7 & $10^{\text {th }}$ \\
Technologies are not resistant to weather conditions & 89 & 37.1 & $11^{\text {th }}$ \\
Indigenous technologies are not fire proof & 76 & 31.7 & $12^{\text {th }}$ \\
Inadequate capacity of available indigenous technologies & 60 & 25.0 & $13^{\text {th }}$ \\
Low viability of seeds after storage and preservation & 40 & 16.7 & $14^{\text {th }}$ \\
High illiteracy level among farmers & 5 & 2.1 & $15^{\text {th }}$ \\
Inadequate finance & 3 & 1.3 & $16^{\text {th }}$ \\
\hline
\end{tabular}

Source: Field survey, 2009

Table 6: Determinants of indigenous technology utilization among farmers

\begin{tabular}{lrrrrr}
\hline & \multicolumn{2}{l}{ Unstandardized } & \multicolumn{2}{l}{$\begin{array}{l}\text { Standardized } \\
\text { coefficient }\end{array}$} & \multicolumn{1}{l}{ coefficient } \\
& $\mathrm{B}$ & Std. Error & Beta (b) & \multicolumn{1}{c}{ t } & p-value \\
\hline Constant & 53.201 & 5.159 & - & 10.312 & 0.01 \\
Age & 0.140 & 0.68 & 0.174 & $2.073^{*}$ & 0.039 \\
Years of formal education & 1.054 & 0.375 & 0.225 & $2.808^{* *}$ & 0.005 \\
Number of valued & 2.77 & 0.382 & -0.029 & $3.497^{* *}$ & 0.002 \\
Technology characteristics & & & & & \\
Years of farming experience & -0.351 & 0.551 & -0.048 & -1.245 & 0.214 \\
Farm size & -3.62 & 0.00 & 0.084 & -1.245 & 0.214 \\
Number of crops planted & 119.20 & 0.111 & -0.03 & $3.11^{* *}$ & 0.01 \\
Monthly income & 195.90 & 0.317 & -0.14 & $-4.811^{* *}$ & 0.01 \\
Number of information sources & 4.95 & 0.021 & 0.05 & $-2.210^{*}$ & 0.05 \\
\hline
\end{tabular}

Note: $\mathrm{R}=0.81 ; \mathrm{R}^{2}=0.656 ; \mathrm{F}=371.321, \mathrm{n}=240$.

$* \mathrm{p}<0.05, * * \mathrm{p}<0.01$ indicate level of significance at $5 \% \& 1 \%$ respectively.

Source: Field survey, 2009

However, farmers' monthly income and number of information sources used by farmers were significant but negative. These imply that farmers with high monthly income and exposure to many information sources rely less on indigenous storage and preservation technologies. Similarly, high exposure to western education may positively influence farmers' usage of indigenous technologies in crop storage and preservation. Literature has established that number of years spent in formal education influenced adoption and utilization of agricultural technologies (Kassahun and Adey, 2013; Beshir et al., 2012). Furthermore, the significant influence of technology characteristics points to the fact that indigenous technology possess some valued qualities which farmers consider suitable and culturally compatible in time and space (Kolawole, 2001). These valued characteristics should be considered in any planned improved technology to enhance its acceptability.

\section{CONCLUSIONS AND RECOMMENDATIONS}

The study revealed that all the farmers in the study areas used various indigenous storage and preservation technologies for arable crops. However, most of the indigenous technologies identified and seen were no longer used by most farmers. Empirical evidence emerging from the results of the findings established technology gap between male and female farmers with the females generally using more technologies than the males. However, there was a widespread gap between male and female in the utilization of yam barn and maize cribs in favour of the males. With the two crops (yam and maize) fast becoming economic crops, their monopoly by the males may imply further perpetration of women in poverty unless the identified gap is bridged by paying attention to the needs and interest of both gender in the improvement of technologies. 
Also, the technologies utilized vary according to crops. More technologies were used for storage and preservation of cassava, maize and yam while fewer were used for tomatoes, leafy vegetables and pepper despite their perishable nature. It was also revealed that farmers stored and preserved arable crops under many cons traints. In addition, years of farming experience, number of years spent in formal education, age, number of crops planted, monthly income, and the number of information sources were the important predictors of indigenous storage and preservation technology utilization among farmers in the study area. Based on the findings, affordability, availability, compatibility with culture, safety from harmful substances, easy usage, environmental friendliness and few available alternative technologies were reasons for utilization of indigenous technologies among the farmers. Hence, to enhance rural agricultural development, it is important that urgent steps be embarked upon to improve the existing indigenous crop storage and preservation technologies used by farmers.

How can Farmers' technology options be expanded to enhance rural agricultural development? The improvement on farmers' indigenous technologies is crucial to the expansion of technology options which may necessitate the consideration of the following:

1. An assessment carried out on indigenous knowledge will expose both the strength and weaknesses of technologies used and proffer possible solutions to bridging identified gaps by promoting its strength.

2. Integrated research involving all agricultural stakeholders will enhance the development of improved technologies that would be adapted to farmers' situation for more acceptable and sustainable agricultural development. This may necessitate the ownership of Research Institutes by states instead of the present policy of sole ownership by the Federal Government while the states only operate extension services.

3. Giving equal attention to all crops and both male and female in the development of technology will bridge the existing gaps between crops and gender.

4. There is the need to reconcile the gap between policy and its implementation within the reality of farmers' environment. The Farm System Research if properly implemented will make developed technologies more appropriate for farmers' use.

5. Promoting cooperative ownership of technologies used for storage and preservation of farm produce by poor resource farmers will enhance pulling resources together for better acquisition, management and utilization of such facilities. This step will encourage the use of bigger structure, reduce cost, enhance security of farm produce and promote better interactions among farmers.

6. Co-operation between important traditional institutions and appropriate formal security agencies will enhance safety of farm produce and make the present under-utilized outdoor storage technologies more attractive to farmers.

\section{REFERENCES}

ABDULlAHI, A., USMAN, I. S., GIREI, A. A. \& ISMA'IL, G. (2016). Examination of indigenous storage methods of cowpea (Vigna Unguiculata) in Mubi South Local Government Area, Adamawa State, Nigeria. Scientific Papers Series Management, Economic Engineering in Agriculture and Rural Development, 16(2), p. $9-16$.

ADEKUNLE, O. A. \& NANBITA, R. I. (2006). Indigenous Storage Structures for Cereals by Woman Farmers in Kaltungo Area of Gombe State. Journal of Central European Agriculture, 7(31), p. 435 - 438. e1882. DOI: http://dx.doi.org/10.4236/oalib.1101882

ADIAHA, M. S. (2017). Complete Guide to Agricultural Product Processing and Storage. World Scientific News, 81(1), p. 1 - 52. Available at: http://www.worldscientificnews.com

AGEA, J. G., LUGANGWA, E., OBUA, J. \& KAMBUGU, R. K. (2008). Role of Indigenous Knowledge in Enhancing Household Food Security: A Case Study of Mukungwe, Masaka District, Central Uganda. Indilinga - African Journal of Indigenous Knowledge Systems, 17, p. 64-71.

AJANI, E. N., \& ONWUBUYA, E. A. (2012). Assessment of use of indigenous maize storage practices among farmers in Anambra State, Nigeria. Int. J. Agric. Res. Innov. \& Tech. 2 (2), p. $48-53$

ALONGE, A. F. (2011). Food Processing, Preservation and Storage for Economic Development in Nigeria. Proceedings of the $11^{\text {th }}$ International Conference and $32^{\text {nd }}$ Annual General Meeting of the Nigerian Institution of Agricultural Engineers held at Ilorin, Nigeria between October 17 and 20, 2011. Vol. 32, p. 57 - 64. ISBN: 978036-578-8

ARINZE, E. A., \& OYI, A. (1989). Traditional grain storage structures in Nigeria: Past and present practices and future possibilities. Crop Storage in Nigeria. Vol. 1. Seminar Proc. Federal Ministry of Agriculture, Water Resources and Rural Development, Pp. 80-87.

AROWOLO, D. (2010). The effects of western civilisation and culture on Africa. Afro-Asian Journal of Social sciences $1(1)$

AWORH, O. C (2008). The Role of Traditional Food Processing Technologies in National Development: The West African Experience. International Union of Food Science \& Technology. Pp 1-18.

BESHIR, H., EMANA, B., KASSA, B. \& HAJI, J. (2012). Determinants of chemical fertilizer technology adoption in North eastern highlands of Ethiopia: The double hurdle approach. Journal of Research in Economics and International Finance (JREIF) Vol. 1(2) pp. 39-49.

CHIKAIRE, J., OSUUAGHU, C. O., IHEANACHO, R. A., OGUEGBUCHULAM, M. N., EJIOGU-OKEREKE, N. \& OBI, K.U., (2012). Indigenous knowledge system; the need for reform and the way forward. Global Advanced Research Journal of Agricultural Science 1(8), p. $201-209$ 
DNS (1995). The Directory of Nigerian Statisticians, Vol. 2: 46-71

FAO (2010). FAO/ World Bank workshop on reducing post-harvest losses in grain supply chains in Africa: Lessons learned and practical guidelines.

FAO (2014). Food Loss Assessments: Causes and Solutions.

FAO, (2011). Global food losses and food waste; extent, causes and prevention. Food and Agriculture Organization of the United States, Rome

FASOYIRO, S. B., \& TAIWO, K. A. (2012). Strategies for Increasing Food Production and Food Security in Nigeria Journal of Agricultural \& Food Information, 13, p. 338-355.

DOI:

https://doi.org/10.1080/10496505.2012.715063

GERVAIS, D. (2005). Traditional Knowledge and Intellectual Property: A TRIPS Compatible Approach, Michigan State Law Review 137

GUSTAVSSON, J., CEDERBERG, C., SONESSON, U., Van OTTERDIJK, R. and MEYBECK, A. (2011). Global Food Losses and Food Waste; Food and Agriculture Organization of the United Nations: Rome, Italy, 2011.

HODGES, R. J., BUZBY, J. C, \& BENNETT, B. (2011). Post-harvest losses and waste in developed and less developed countries: opportunities to improve resource use. Journal of Agricultural Science, (149), p. 37 - 45. DOI: https://doi.org/10.1017/S0021859610000936

IFAD, WFP \& FAO, (2012): The Sate of Food Insecurity in the World: Economic Growth is Necessary, but not Sufficient to Accelerate Reduction of Hunger And Malnutrition. In: UNITED NATIONS. (ed.). Rome: FAO. IFEOMA, J. I. \& AGWU, E. A. (2014). Assessment of Food Security Situation among Farming Households in Rural Areas of Kano State, Nigeria. J. Central European Agriculture, 15(1), p. 94 - 107. DOI: https://doi.org/10.5513/jcea.v15i1.2443

IVBIJARO, M. F. (1989). Research advances in the postharvest technology of crops. Paper presented at the seminar on crop storage in Nigeria, Dec 11-13. Seminar proceeding, Vol.1, pp 99-106. Federal Ministry of Agriculture, Water Resources and Rural Development.

KASSAHUN, J. J \& ADEY, M. (2013). Factors affecting the level of adoption of dairy technologies in Ada'a and Lume Districts, East Shoa-Ethiopia. Agricultural Science Research Journals Vol. 3(8), pp. 237-243.

KOLAWOLE, O. D. (2001). Local knowledge utilization and sustainable rural development in the $21^{\text {st }}$ century. The Hague Indigenous Knowledge and Development Monitor 9(3): 13-15.

LABADARIOS, D., MCHIZA, J., STEYN, P., GERICKE, G., MAUNDER, E., DAVIDS, D. \& PARKER, W. (2011). Food Security in South Africa. A Review of National Surveys. In: Human Nutrition, U. O. P. (ed.). Pretoria, South Africa: Human Sciences Research Council.

LIPINSKI, B., HANSON, C., LOMAX, J., KITINOJA, L., WAITE, R. and SEARCHINGER, T. (2013). Installment 2 of "Creating a Sustainable Food Future" Reducing Food Loss and Waste; Working Paper; World Resource Institute: Washington, DC, USA.

MAGNI, G. (2016). Indigenous knowledge and implications for the sustainable development agenda:
Education for people and planet: Creating sustainable futures for all. UNESCO Background paper prepared for the 2016 Global Education Monitoring Report.

MBUK, E. M., BASSEY, N. E., UDOH, E. S. \& UDOH, E. J. (2011). Factors Influencing Post Harvest Loss of Tomatoes in Urban Market in Uyo, Nigeria. Nigerian Journal of Agriculture, Food and Environment. 7(2):4046.

MERCER, J., DOMINEY-HOWES, D., KELMAN, I. \& LLOYD, K. (2007). The Potential for Combining Indigenous and Western Knowledge in Reducing Vulnerability to Environmental Hazards in Small Island Developing States. Environmental Hazards, 7, p. 245 256. DOI: https://doi.org/10.1016/j.envhaz.2006.11.001

NATIONAL BUREAU OF STATISTICS, (2007). Social Statistics in Nigeria 2007. Federal Republic of Nigeria. National Bureau of Statistics.

NATIONAL POPULATION COMMISSION (2006). State population. Retrieved from http://www.population.gov.ng/index.php/statepopulation.

NEGI, T., \& SOLANKI, D. (2015). Tradition Grain Storage Structures and Practices Followed by Farm Families of Kumaon Region in Uttarakhand. Indian Res. J. Ext. Edu. 15(4), p $137-141$.

NWANKITI, A. D. O., \& MAKURDI, A. O. (1989). Traditional and some improved storage methods for tuber crops in Nigeria. In: Entwicklung D.S.E (Ed), Roots, tubers and legumes. Deutsche Stifftung fur Internationale, Bonn. Pp 51-67.

OLUMEKO, D. O. (1996). Technical survey evaluation and economic review of storage structures in Nigeria. M.Phil Thesis, Department of Agricultural Engineering, University of Ibadan, Nigeria, pp. 110.

PARROTTA, J. A. \& AGNOLETTI, M. (2007). Traditional forest knowledge: Challenges and Opportunities. Forest ecology and Management: 249, (12), 1-4. http://dx.doi.org/10.1016/j.foreco.2007.05.022

PASU, E. (1988). Crop storage Unit. Field of existing storage structures in Nigeria. CSU Pamphlet, Ibadan, Oyo State.

ROOS, V., CHIGEZA, S. \& VAN NIEKERK, D. (2010). Coping With Drought: Indigenous Knowledge Application In Rural South Africa. Indilinga - African Journal of Indigenous Knowledge Systems, 9, 1-11.

SEKUMADE, A. B \& OLUWATAYO, I. B. (2009). Comparative analysis of maize storage technologies in Kwara State, Nigeria. Int. J. Sustain. Crop Prod. 4(5), p. $24-31$.

SINGH, R. K. P. \& SATAPATHY, K. K. (2003). Zero Energy Cool Chamber: A Low Cost Storage Structure. Journal of the North Eastern Council, 23(3): p. 30.

SOETAN, R. A, AYINDE, J. O \& KOLEDOYE, G. F. (2013). Factor influencing access to resources by Fadama Women Users' Group (FUG) in Osun State, Nigeria. Spanish Journal of Rural Development. Vol. 5 (1): 12-19.

TITILOLA, TUNJI; EGUNJOBI, LAYI; AMUSAN, AGBO \& WAHAB, BOLANLE (1994). Introduction of Indigenous Knowledge into the Education Curriculum of Primary, Secondary and Tertiary Institution in Nigeria: A Policy Guidelines, CIKARO, Ames. 
TSIKO, S. (2009). Zimbabwe: Indigenous Vegetable Policy Framework Crucial. Harare, Government of Zimbabwe.

UNESCO (2007). Havana Communiqué on Cultural Mapping, adopted at the International Workshop on Cultural Mapping held within the framework of the Regional Meeting entitled "New Perspectives on Cultural Diversity: The Role of Communities", Havana, Cuba 7 10 February 2006

UNESCO (2009). Learning and Knowing in Indigenous Societies Today. In: P. BATES, M. C., S. KUBE \& D. NAKASHIMA, (ed.). UNESCO, Paris.

UNICEF/WHO/World Bank (2013). Levels and Trends in Child Malnutrition: Joint child malnutrition estimates" available online at: http://www.who.int/entity/nutgrowthdb/jme unicef who wb.pdf
VERMA, S. K. (2004). Protecting Traditional Knowledge; Is a Sui Generis System an Answer? The Journal of World Intellectual Property, 7(6), pp. 769 $770 . \quad$ DOI: $\quad$ https://doi.org/10.1111/j.17471796.2004.tb00228.x

VERMA, T., ROY, S. \& SWARNALATHA, A. M. (2005). Eco friendly grain storage structures in India. Asian Agri. History; 9(3), p. 231 - 241

WHO (2003). Global database on Child growth and Malnutrition. Geneva, World Health Organization (www.who.int/nutgrowthdb

WORLD BANK (2008). World Bank's Indigenous Peoples

Program. 